\title{
Desempenho produtivo e econômico do consórcio de cafeeiro arábica e nogueira-macadâmia
}

\author{
Marcos José Perdoná(1), Rogério Peres Soratto(2) e Maura Seiko Tsutsui Esperancini(3)
}

\begin{abstract}
(1)Agência Paulista de Tecnologia dos Agronegócios, Regional Centro-Oeste, Avenida Rodrigues Alves, no 4040, CEP 17030-000 Bauru, SP, Brasil. E-mail: marcosperdona@apta.sp.gov.br (2)Universidade Estadual Paulista (Unesp), Faculdade de Ciências Agronômicas, Departamento de Produção e Melhoramento Vegetal, Campus de Botucatu, Caixa Postal 237, CEP 18610-307 Botucatu, SP, Brasil. E-mail: soratto@fca.unesp.br (3)Unesp, Faculdade de Ciências Agronômicas, Departamento de Economia, Sociologia e Tecnologia. CEP 18610-307 Botucatu, SP, Brasil. E-mail: maura@fca.unesp.br
\end{abstract}

Resumo - O objetivo deste trabalho foi avaliar o desempenho produtivo e econômico do consórcio de cafeeiro arábica e nogueira-macadâmia, em condições de sequeiro e irrigado por gotejamento, bem como a viabilidade financeira dos tratamentos em três cenários de preço de café. Utilizou-se o delineamento experimental inteiramente casualizado, com seis tratamentos (café solteiro sequeiro, café solteiro irrigado, consórcio café-nogueira-macadâmia sequeiro, consórcio café-nogueira-macadâmia irrigado, nogueira-macadâmia solteira sequeiro e nogueira-macadâmia solteira irrigada) e dez repetições. Avaliaram-se a produtividade, o índice de equivalência de área e os resultados econômicos dos tratamentos em três cenários de preço do café. A irrigação por gotejamento e o cultivo consorciado aumentaram a produtividade do cafeeiro e da nogueira-macadâmia, em comparação aos monocultivos em condição de sequeiro, e, em geral, proporcionaram a mesma produtividade dos monocultivos irrigados de café, além de produtividade superior à dos monocultivos irrigados de nogueira-macadâmia. $\mathrm{O}$ uso associado da consorciação e da irrigação aumenta a eficiência do uso da terra em cinco vezes, quando comparado às médias das culturas solteiras em condição de sequeiro. $\mathrm{O}$ cultivo consorciado irrigado proporciona maior rentabilidade e retorno mais rápido do investimento, o que o torna uma alternativa viável, especialmente em períodos de menores preços do café.

Termos para indexação: Coffea arabica, Macadamia integrifolia, consorciação, irrigação por gotejamento, preço de venda do café, rentabilidade.

\section{Productive and economic performance of Arabica coffee and macadamia nut intercropping}

\begin{abstract}
The objective of this work was to evaluate the productive and economic performance of Arabica coffee and macadamia nut intercropping, under rainfed and drip-irrigation conditions, as well as the financial viability of treatments in three coffee price scenarios. A completely randomized design was used, with six treatments (rainfed sole coffee, irrigated sole coffee, rainfed coffee-macadamia nut intercropping, irrigated coffee-macadamia nut intercropping, rainfed sole macadamia nut, and irrigated sole macadamia nut) and ten replicates. The productivity, the area equivalency index, and the economic outcomes of the treatments were evaluated in three coffee price scenarios. Drip irrigation and intercropping increased coffee and macadamia nut yields, in comparison to rainfed monocultures, and generally promoted the same productivity as the coffee irrigated monocultures, as well as higher productivity than the macadamia nut irrigated monocultures. The combined use of intercropping and drip irrigation promotes land-use efficiency 5 -fold greater than the averages of rainfed monocultures. Irrigated intercropping promotes higher profitability and faster return on investment, making it a viable alternative, especially in periods of lower coffee prices.
\end{abstract}

Index terms: Coffea arabica, Macadamia integrifolia, intercropping, drip irrigation, coffee selling price, profitability.

\section{Introdução}

Da mesma forma que em outras regiões brasileiras, a área cultivada com cafeeiro tem diminuído expressivamente no Estado de São Paulo. Em 2013, aproximadamente 7.250 ha de cafeeiro foram erradicados (Acompanhamento da Safra Brasileira, 2014), e, na última década, houve redução de $22,6 \%$ na área de cafeeiro, que passou de 227,8 mil para 185,8 mil hectares (Instituto de Economia Agrícola, 2014). Ao mesmo tempo, os custos de produção apresentaram aumento expressivo nesse período. 
O custo médio da diária de um trabalhador passou de $\mathrm{R} \$ 13,90$ para $\mathrm{R} \$ 48,98$, e o custo da terra, importante componente na formação do custo de produção dos produtos agrícolas, aumentou em 178\% (Instituto de Economia Agrícola, 2014). Assim, as produtividades alcançadas nas lavouras tradicionais de cafeeiro no estado, de 24,7 sacas por hectare (Acompanhamento da Safra Brasileira, 2014), tem sido, na maioria das vezes, insuficientes para obtenção de rentabilidade satisfatória e viabilidade econômica, o que tem dificultado a manutenção da sustentabilidade do agronegócio do café no Estado de São Paulo.

Reconfigurações geográficas da cafeicultura provocam profundas modificações na infraestrutura, na mão de obra, na prestação de serviços, no transporte e no escoamento da produção de uma região, além de acarretarem sérios prejuízos econômicos, sociais e ambientais (Assad et al., 2004; Deconto, 2008). Dessa forma, modificações nos atuais modelos de cultivo são necessárias para modernizar os sistemas produtivos e torná-los novamente viáveis.

Uma das alternativas, apesar de exigir considerável investimento, é o uso da irrigação, que tem se mostrado eficiente para o incremento da produtividade da cultura do cafeeiro arábica (Coffea arabica L.) no Brasil, o que também pode melhorar a viabilidade econômica e a sustentabilidade desse cultivo (Arruda \& Grande, 2003; Silva et al., 2003; Arêdes et al., 2010; Oliveira et al., 2010; Perdoná et al., 2012b). Outra alternativa é a consorciação do cafeeiro com diferentes culturas, o que pode melhorar a viabilidade da cafeicultura, sem requerer investimentos muito elevados, e proporcionar renda adicional ao empreendimento (Nicoleli \& Moller, 2006; Silva et al., 2012). Esse fator é fundamental quando se considera a condição da maioria dos cafeicultores, que são agricultores familiares (Acompanhamento da Safra Brasileira, 2014) com baixa capacidade de investimento. O consórcio de espécies florestais de alto valor econômico com o cafeeiro, uma espécie que tolera certo sombreamento, também é interessante, especialmente no caso de pequenas propriedades (Elevitch et al., 2009).

A consorciação com nogueira-macadâmia (Macadamia integrifolia Maiden \& Betche) vem sendo utilizada pelos produtores, em diversas regiões cafeeiras, desde a década de 1970, e tem potencial para proporcionar uma fonte adicional de renda aos cafeicultores e de melhorar as condições ambientais no cultivo do café arábica (Elevitch et al., 2009; Perdoná et al., 2012a). Pezzopane et al. (2010) observaram redução de $72 \%$ na intensidade dos ventos e de $2,2^{\circ} \mathrm{C}$ na temperatura média nesse consórcio, condições benéficas aos cafeeiros, principalmente frente à possibilidade do aquecimento global. No Havaí, Elevitch et al. (2009) relataram que o cultivo de cafezais arborizados com nogueira-macadâmia sequestraram, em média, 6,7 $\mathrm{Mg} \mathrm{ha}^{-1}$ de carbono a mais que os cafezais a pleno sol. Outros benefícios foram verificados, como melhoria na fertilidade do solo e na qualidade da bebida (Vaast et al., 2006), diminuição da bienalidade de produção dos cafeeiros e redução da ocorrência de plantas daninhas (Elevitch et al., 2009; Silva et al., 2013), bem como melhor aproveitamento da mão de obra (Aparecido et al., 2014) e elevado retorno financeiro (Elevitch et al., 2009; Chung et al., 2013). Entretanto, o uso dessa nogueira dificulta a mecanização da colheita do café e, na ausência de um adequado manejo de podas, pode provocar diminuição da produtividade dos cafeeiros (Steiman et al., 2011; Perdoná et al., 2012a), o que põe em dúvida a viabilidade econômica em sistemas mecanizados e a sustentabilidade desse consórcio.

O cultivo solteiro da nogueira-macadâmia tem crescido nos últimos anos no Estado de São Paulo. No entanto, encontra dificuldades em sua expansão, por conta do elevado período de retorno do investimento, nessa modalidade de cultivo (Pimentel et al., 2007), condição que também poderá ser modificada pelo uso da irrigação e da consorciação na cultura. Desse modo, o uso da irrigação ou da consorciação com a nogueira-macadâmia, no cultivo do cafeeiro, e a associação entre essas tecnologias podem ser alternativas para melhorar a eficiência de uso da terra e evitar a decadência da cafeicultura, sobretudo em período de menores preços do café.

O objetivo deste trabalho foi avaliar o desempenho produtivo e econômico do consórcio de cafeeiro arábica e nogueira-macadâmia, em condições de sequeiro e irrigado por gotejamento, bem como a viabilidade financeira dos tratamentos considerando três cenários de preço de café.

\section{Material e Métodos}

$\mathrm{O}$ experimento foi realizado em uma propriedade localizada no Município de Dois Córregos, SP $\left(22^{\circ} 21^{\prime} \mathrm{S}\right.$ 
e $48^{\circ} 22^{\prime} \mathrm{W}$, a $753 \mathrm{~m}$ de altitude). O solo do local é um Latossolo Vermelho-Amarelo distrófico (Santos et al., 2006). O clima da região, segundo a classificação de Köppen, é caracterizado como Cwa, tropical, com estação seca no inverno, temperatura média anual de $21,2^{\circ} \mathrm{C}$ e regime pluvial anual de $1.342 \mathrm{~mm}$ (Centro de Pesquisas Meteorológicas e Climáticas Aplicadas à Agricultura, 2014). Os dados climáticos do período experimental estão descritos na Tabela 1 .

Utilizou-se o delineamento inteiramente casualizado, com seis tratamentos (café solteiro sequeiro, café solteiro irrigado, consórcio de cafeeiro com nogueira-macadâmia sequeiro, consórcio de cafeeiro com nogueira-macadâmia irrigado, nogueira-macadâmia solteira sequeiro e nogueira-macadâmia solteira irrigada) e dez repetições. Cada unidade amostral foi composta de uma área de 4,9x10,5 $\mathrm{m}\left(51,5 \mathrm{~m}^{2}\right)$, que continha
21 cafeeiros em cultivo solteiro; 20 cafeeiros e uma nogueira-macadâmia, em consórcio; e uma nogueira-macadâmia no cultivo de macadâmia solteira (Figura 1).

Antes da instalação do experimento, foi realizada a caracterização química e granulométrica do solo, na camada de $0-20 \mathrm{~cm}$ de profundidade, que apresentou as seguintes características: $\mathrm{pH}$ em $\mathrm{CaCl}_{2}$ de 5,$2 ; 5 \mathrm{mg}$ $\mathrm{dm}^{-3}$ de P resina; $17 \mathrm{~g} \mathrm{dm}^{-3}$ de MO; $0,8 \mathrm{mmol}_{\mathrm{c}} \mathrm{dm}^{-3} \mathrm{de}$ $\mathrm{K} ; 9 \mathrm{mmol}_{\mathrm{c}} \mathrm{dm}^{-3} \mathrm{de} \mathrm{Ca} ; 7 \mathrm{mmol}_{\mathrm{c}} \mathrm{dm}^{-3} \mathrm{de} \mathrm{Mg} ; 1 \mathrm{mmol}_{\mathrm{c}}$ $\mathrm{dm}^{-3}$ de $\mathrm{Al} ; 18 \mathrm{mmol}_{\mathrm{c}} \mathrm{dm}^{-3}$ de $\mathrm{H}+\mathrm{Al}$; saturação por bases de 49\%; $3 \mathrm{mg} \mathrm{dm}^{-3}$ de S-SO ${ }_{4}{ }^{2-} ; 0,12 \mathrm{mg} \mathrm{dm}^{-3} \mathrm{de}$ $\mathrm{B}$ (água quente); $0,4 \mathrm{mg} \mathrm{dm}^{-3}$ de $\mathrm{Cu}$ (DTPA); $20 \mathrm{mg}$ $\mathrm{dm}^{-3}$ de Fe (DTPA); 3,6 mg dm${ }^{-3}$ de Mn (DTPA); $0,6 \mathrm{mg} \mathrm{dm}^{-3}$ de $\mathrm{Zn}$ (DTPA); 10,3\% de argila; 7,1\% de silte; e $82,6 \%$ de areia. As culturas foram plantadas em fevereiro de 2006. Antes da implantação das culturas, $1.300 \mathrm{~kg} \mathrm{ha}^{-1}$ de calcário dolomítico foram distribuídos

Tabela 1. Temperaturas médias e precipitações pluviais mensais e irrigação anual, no período de condução do experimento, de fevereiro de 2006 a março de 2013.

\begin{tabular}{|c|c|c|c|c|c|c|c|c|}
\hline Mês & 2006 & 2007 & 2008 & 2009 & 2010 & 2011 & 2012 & 2013 \\
\hline & \multicolumn{8}{|c|}{ Temperatura média $\left({ }^{\circ} \mathrm{C}\right)$} \\
\hline Janeiro & - & 24,7 & 24,0 & 24,1 & 25,2 & 26,3 & 21,5 & 24,3 \\
\hline Fevereiro & 25,3 & 25,3 & 24,7 & 25,4 & 25,6 & 26,5 & 24,1 & 25,3 \\
\hline Março & 25,5 & 25,7 & 24,6 & 25,1 & 24,7 & 25,0 & 22,5 & 25,5 \\
\hline Abril & 22,4 & 24,9 & 23,0 & 23,0 & 23,2 & 23,5 & 21,5 & - \\
\hline Maio & 18,5 & 19,5 & 19,3 & 20,7 & 20,1 & 19,7 & 17,9 & - \\
\hline Junho & 19,3 & 20,5 & 19,0 & 17,2 & 18,7 & 18,6 & 17,4 & - \\
\hline Julho & 20,8 & 18,2 & 19,7 & 19,5 & 20,5 & 19,8 & 17,6 & - \\
\hline Agosto & 21,9 & 21,0 & 22,0 & 19,5 & 20,3 & 19,8 & 19,3 & - \\
\hline Setembro & 21,4 & 24,3 & 21,1 & 22,2 & 22,9 & 23,1 & 20,9 & - \\
\hline Outubro & 23,8 & 24,7 & 23,6 & 22,3 & 22,8 & 22,5 & 22,9 & - \\
\hline Novembro & 25,0 & 23,6 & 24,2 & 25,8 & 24,9 & 23,7 & 22,4 & - \\
\hline \multirow[t]{2}{*}{ Dezembro } & 25,1 & 24,1 & 24,2 & 23,9 & 25,6 & 25,3 & 24,4 & - \\
\hline & \multicolumn{8}{|c|}{ Precipitação pluvial (mm) } \\
\hline Janeiro & - & 434 & 200 & 399 & 237 & 435 & 304 & 365 \\
\hline Fevereiro & 203 & 221 & 194 & 176 & 160 & 153 & 142 & 176 \\
\hline Março & 232 & 150 & 163 & 160 & 143 & 188 & 134 & 204 \\
\hline Abril & 33 & 94 & 162 & 23 & 67 & 92 & 208 & - \\
\hline Maio & 1 & 68 & 79 & 75 & 24 & 12 & 71 & - \\
\hline Junho & 16 & 11 & 52 & 51 & 17 & 37 & 177 & - \\
\hline Julho & 46 & 273 & 0 & 93 & 55 & 5 & 41 & - \\
\hline Agosto & 14 & 0 & 49 & 86 & 0 & 75 & 0 & - \\
\hline Setembro & 68 & 0 & 52 & 229 & 77 & 19 & 26 & - \\
\hline Outubro & 167 & 76 & 115 & 94 & 93 & 170 & 100 & - \\
\hline Novembro & 232 & 275 & 79 & 264 & 86 & 276 & 90 & - \\
\hline \multirow[t]{2}{*}{ Dezembro } & 299 & 272 & 130 & 356 & 326 & 206 & 137 & - \\
\hline & \multicolumn{8}{|c|}{ Irrigação anual (mm) } \\
\hline Quantidade anual & 205 & 237 & 321 & 167 & 288 & 152 & 234 & 12 \\
\hline
\end{tabular}


e incorporados ao solo à profundidade de $0,25 \mathrm{~m}$, com uso de grade aradora.

As mudas de café da cultivar Obatã IAC 1669-20 foram plantadas em espaçamento de $3,5 \times 0,7 \mathrm{~m}$ (4.082 plantas por hectare), e as de nogueira-macadâmia da cultivar IAC 9-20 foram enxertadas sobre o porta-enxerto Aloha IAC 10-14, no espaçamento de 10,5 $\times 4,9 \mathrm{~m}$ (194 plantas por hectare). No cultivo consorciado, foram utilizados os mesmos espaçamentos dos cultivos solteiros para cada cultura. As fileiras de nogueira-macadâmia coincidiram com as de cafeeiros (Figura 1C). Nessas fileiras, entre duas nogueiras, havia seis cafeeiros. Portanto, foram plantados 3.887 cafeeiros e 194 plantas de nogueira-macadâmia por hectare.

As plantas de café foram adubadas conforme recomendações de Raij et al. (1997), com base na idade das plantas ou nas estimativas de safra de cada ano e no tratamento irrigado como padrão. Já as plantas de nogueira-macadâmia foram adubadas seguindo as recomendações de Quaggio et al. (1997). No plantio do cafeeiro, foram distribuídos e incorporados, em cada metro de sulco, $60 \mathrm{~g}$ de $\mathrm{P}_{2} \mathrm{O}_{5}$ (superfosfato simples), $20 \mathrm{~g}$ de $\mathrm{K}_{2} \mathrm{O}$ (cloreto de potássio), $250 \mathrm{~g}$ de calcário dolomítico com PRNT de $74 \%$ e 5 L de cama de frango. No primeiro ano, foram aplicados $40 \mathrm{~g}$ de $\mathrm{N}$ (ureia) e $40 \mathrm{~g}$ de $\mathrm{K}_{2} \mathrm{O}$ por metro de fileira, parcelado em cinco vezes. Nos anos seguintes, as quantidades de $\mathrm{N}-\mathrm{P}_{2} \mathrm{O}_{5}-\mathrm{K}_{2} \mathrm{O}$, na forma de adubo formulado (ureia, superfosfato e cloreto de potássio), em $\mathrm{kg} \mathrm{ha}^{-1}$, aplicadas foram: 160-40-160 em 2007/2008; 200-50-200 em
2008/2009; 500-80-500 em 2009/2010; 160-50-160 em 2010/2011; e 500-80-500 em 2011/2012. Em cada cova de plantio de nogueira-macadâmia, foram adicionados $160 \mathrm{~g}$ de $\mathrm{P}_{2} \mathrm{O}_{5}, 60 \mathrm{~g}$ de $\mathrm{K}_{2} \mathrm{O}, 250 \mathrm{~g}$ de calcário dolomítico com PRNT de $74 \%$ e $4 \mathrm{~L}$ de cama de frango. No primeiro ano, aplicou-se $60 \mathrm{~g}$ de $\mathrm{N}$ (ureia). Nos anos seguintes, aplicou-se adubo formulado $\mathrm{N}-\mathrm{P}_{2} \mathrm{O}_{5}-\mathrm{K}_{2} \mathrm{O}$, em kg ha-1, nas quantidades de: $10-10-10$ em 2007/2008; 20-20-20 em 2008/2009; e 50-12-50 em 2009/2010, 2010/2011 e 2011/2012. Em todos os anos, as adubações foram parceladas em quatro vezes (outubro a março). Nos tratamentos consorciados, as plantas foram adubadas separadamente, com as adubações citadas acima. Em cada ano agrícola, foram realizadas três pulverizações nas folhas com ácido bórico $\left(3 \mathrm{~g} \mathrm{~L}^{-1}\right)$, hidróxido de cobre $\left(2 \mathrm{~g} \mathrm{~L}^{-1}\right)$ e sulfato de zinco $\left(6 \mathrm{~g} \mathrm{~L}^{-1}\right)$. Além disso, todos os tratamentos receberam em superfície mais $1.000 \mathrm{~kg} \mathrm{ha}^{-1}$ de calcário dolomítico em 2008, 2010 e 2012.

Nos tratamentos irrigados, a irrigação por gotejamento foi instalada em fevereiro de 2006, anteriormente ao plantio das mudas. Foram utilizados gotejadores autocompensantes, espaçados em $0,7 \mathrm{~m}$ entre si, com vazão de 1,0 L por hora em cada gotejador. $\mathrm{O}$ manejo da irrigação foi realizado com sensores de tensão de água de $25 \mathrm{kPa}$ (sistema Irrigas), instalados nas profundidades de 20 e $60 \mathrm{~cm}$, para manter sempre úmido o sensor instalado a $20 \mathrm{~cm}$.

No café solteiro e no consórcio, o controle de plantas daninhas no primeiro ano foi realizado com uma roçada mecanizada nas entrelinhas, duas

A

B

$\mathrm{C}$

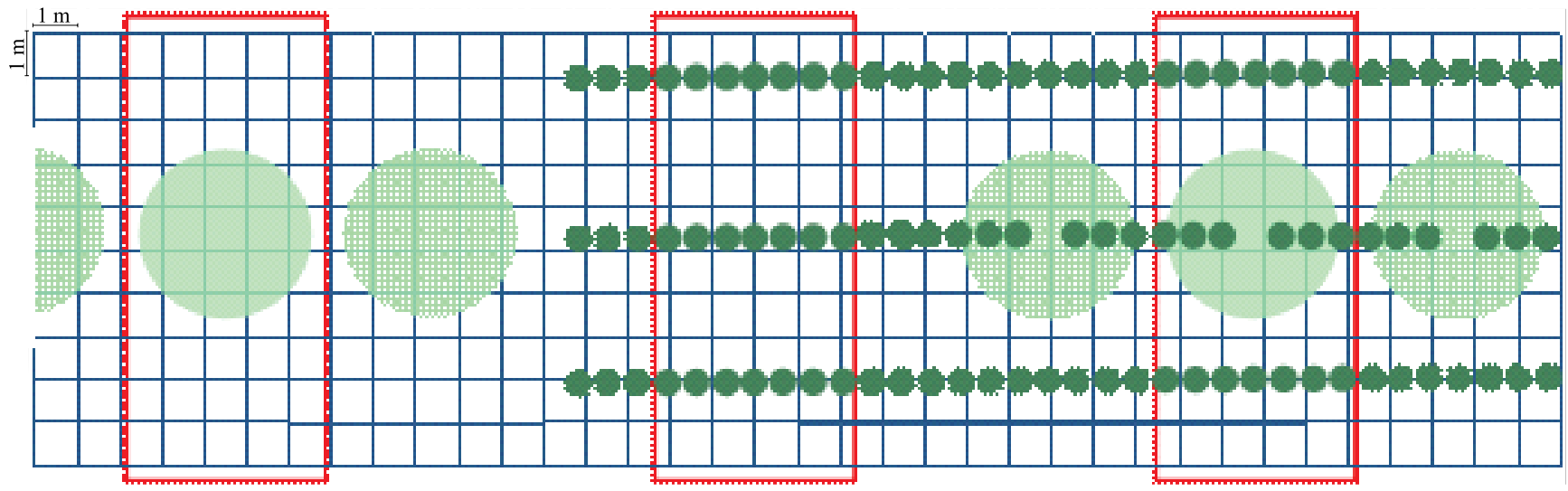

Figura 1. Representação esquemática das unidades amostrais (parcelas) nos sistemas de cultivo: A, nogueira-macadâmia (Macadamia integrifolia) solteira; B, café arábica (Coffea arabica) solteiro; e C, consórcio de café arábica com nogueira-macadâmia. Em verde-claro, plantas de nogueira-macadâmia; em verde-escuro, cafeeiros. 
capinas manuais e aplicação do herbicida oxyfluorfen (240 $\mathrm{g} \mathrm{ha}^{-1}$ do i.a.) nas linhas. A partir do segundo ano, realizou-se uma roçada mecanizada nas entrelinhas e três aplicações do herbicida glifosato $\left(1.426 \mathrm{~g} \mathrm{ha}^{-1} \mathrm{do}\right.$ i.a), em cada ano. Na nogueira-macadâmia solteira, no primeiro ano, foram realizadas duas roçadas mecanizadas nas entrelinhas e duas aplicações de glifosato (1.426 $\mathrm{g} \mathrm{ha}^{-1}$ do i.a.) nas linhas. Nos demais anos, realizou-se uma roçada com duas aplicações de glifosato na linha e uma aplicação na área total (1.426 $\mathrm{g} \mathrm{ha}^{-1}$ do i.a).

O manejo fitossanitário, em todos os tratamentos, foi realizado mediante aplicação de 1,0, 1,0, 1,2, 1,2, 1,2 e $1,2 \mathrm{~kg} \mathrm{ha}^{-1}$ de tiametoxam + ciproconazol (300 + $300 \mathrm{~g} \mathrm{~kg}^{-1}$ do i.a.), via solo, em outubro. Em fevereiro de cada ano, foram aplicados 1,0, 1,0, 1,2, 1,2, 1,2 e $1,2 \mathrm{~kg} \mathrm{ha}^{-1}$ de tiametoxam ( $250 \mathrm{~g} \mathrm{~kg}^{-1}$ do i.a.), via solo, e azoxistrobina + ciproconazol $\left(200+80 \mathrm{~g} \mathrm{~L}^{-1}\right.$ do i.a. $)$, via pulverização nas folhas. A partir de 2009, as plantas de nogueira-macadâmia foram podadas, tendo-se retirado os ramos laterais que se projetavam nas entrelinhas, para a manutenção das operações mecanizadas na lavoura. Contudo, os ramos que se desenvolveram no sentido das fileiras de plantas de cafeeiro não foram podados, para a mínima interferência na produção das plantas de nogueira-macadâmia.

Avaliou-se a produtividade de café beneficiado (sacas por hectare) e de amêndoas de nogueira-macadâmia $\left(\mathrm{kg} \mathrm{ha}^{-1}\right)$, em cinco safras, com a primeira safra de café colhida em julho de 2008 e da nogueira-macadâmia em fevereiro de 2009. Os dados de cada safra e cultura foram submetidos ao teste de normalidade de Lilliefors e de homogeneidade de Cochran \& Bartlett, para verificar o atendimento dos requisitos para o emprego da análise de variância. Os dados de cada cultura foram submetidos à análise da variância, separadamente, e as médias foram comparadas pelo teste de Tukey, a 5\% de probabilidade.

Foram utilizados índices de equivalência de área (IEA) para avaliar a eficiência do consórcio, da irrigação e da associação dessas tecnologias, em relação aos tratamentos de monocultivo (cafeeiro arábica ou nogueira-macadâmia) em condição de sequeiro. Os índices foram obtidos com os valores de produtividade das culturas, em cada tratamento, por meio da equação:

$\mathrm{IEA}=(\mathrm{Cc}$ ou $\mathrm{Ci}$ ou $\mathrm{Cci} / \mathrm{C})+(\mathrm{Mc}$ ou Mi ou Mci / M $)$, em que: Cc é o café consorciado sequeiro; Ci é o café solteiro irrigado; Cci é o café consorciado irrigado; C é o café solteiro sequeiro; Mc é a macadâmia consorciada sequeiro; Mi é a macadâmia solteira irrigada; Mci é a macadâmia consorciada irrigada; e M é a macadâmia solteira sequeiro (Willey \& Osiru, 1972). Assim, as tecnologias de consorciação, irrigação ou ambas foram consideradas eficientes quando o IEA foi superior a 1,0 (Vieira, 1984).

Os valores de entrada e saída de recursos foram registrados, desde as operações de pré-plantio até a quinta safra (agosto de 2012 para o cafeeiro, e fevereiro de 2013 para a nogueira-macadâmia). As estimativas de custo total de produção (CTP) foram elaboradas com os itens adotados pelo Anuário da Agricultura Brasileira (Café, 2011), com uso do custo operacional total (COT), composto das despesas com operações mecanizadas, operações manuais e material consumido, além de juros de custeio e outras despesas, como remuneração da terra. Os custos da irrigação foram computados juntamente com os custos de implantação da cultura, para avaliar qual o período de retorno do investimento, para cada situação. As quantidades de insumos e operações foram tomadas das áreas de plantio, durante o período experimental. Os valores dos insumos e dos serviços foram atualizados para a safra de 2013.

Em razão das grandes variações que ocorrem nos preços do café, utilizaram-se três valores para o preço de venda da saca de $60 \mathrm{~kg}$ : $\mathrm{R} \$ 307,00$ por saca, preço mínimo, estabelecido pelo Governo Federal; R \$ 357,40 por saca, preço médio das últimas quatro safras; e $\mathrm{R} \$ 405,41$ por saca, preço médio das últimas duas safras (Cooperativa Regional dos Cafeicultores em Guaxupé, 2013). Para a noz da nogueira-macadâmia, utilizou-se o preço de venda de $\mathrm{R} \$ 17,60 \mathrm{~kg}^{-1}$ de amêndoas, obtido em pesquisa realizada em indústria de processamento da noz. Para determinar o retorno econômico e a viabilidade financeira em cada tratamento, foram estimados os seguintes indicadores: receita bruta (RB), como o produto da quantidade produzida de cada produto pelo preço de venda; resultado econômico acumulado (REA), como a diferença entre a RB e o CTP; valor presente líquido (VLP), que é o somatório dos saldos de caixa líquidos (descontados), obtidos na vida útil do projeto, ao se considerar uma taxa de juros de $6 \%$ ao ano; e a taxa interna de retorno (TIR), que é a taxa de desconto que torna o VPL igual a zero (Silva et al., 2012). 


\section{Resultados e Discussão}

Em 2008, 2009 e 2012, foram obtidas maiores produtividades do cafeeiro nos tratamentos solteiro irrigado e consórcio irrigado, que diferiram significativamente dos tratamentos em condição de sequeiro, independentemente do uso ou não da consorciação com a nogueira-macadâmia (Tabela 2). Na terceira safra (2010), também foram obtidas maiores produtividades do cafeeiro nos tratamentos irrigados; porém, estes não diferiram do consórcio sequeiro. Em 2011, ano de baixa produção, os tratamentos irrigados proporcionaram menores produtividades do cafeeiro, como resultado das elevadas produtividades obtidas nesses tratamentos no ano anterior. Isso é conhecido como bienalidade na produção, no qual as plantas, tendo apresentado elevada produção em um determinado ano, produzem menos no ano seguinte (DaMatta, 2004). Nos cinco anos avaliados, o uso da irrigação incrementou em 72 e $50 \%$ a produtividade do cafeeiro em cultivo solteiro e em cultivo consorciado, respectivamente, quando comparado ao cultivo em condição de sequeiro (Tabela 2). No Estado de São Paulo, Arruda \& Grande (2003) avaliaram a produtividade do cafeeiro arábica em oito biênios e observaram aumento de produtividade pelo uso da irrigação, em cinco deles. Aumentos da produtividade do cafeeiro arábica com o uso de irrigação por gotejamento também foram relatados por Silva et al.
(2003) e Oliveira et al. (2010) em Minas Gerais. Esses aumentos ocorreram porque o estado hídrico das células do cafeeiro afeta sensivelmente a expansão celular, a abertura estomática e a fotossíntese (DaMatta et al., 2007); assim, o uso da irrigação permite maiores produtividades em regiões onde ocorrem deficits hídricos.

Em condição de sequeiro, a consorciação com nogueira-macadâmia incrementou a produtividade do cafeeiro em $30 \%$, em 2012 , e em $10 \%$ no total das cinco safras (Tabela 2). Pezzopane et al. (2010) constataram diminuição na incidência do vento, em $72 \%$, e na média da temperatura máxima do ar, em $2,2^{\circ} \mathrm{C}$, no cultivo de cafeeiro com nogueira-macadâmia, em razão da melhoria das condições ambientais, o que pode justificar esses aumentos. Porém, sob irrigação, a consorciação não afetou significativamente a produtividade do cafeeiro no total das cinco safras, tendo a reduzido em 12\%, em 2012 (Tabela 2).

Com relação à nogueira-macadâmia, nas quatro primeiras safras $(2009,2010,2011$ e 2012), as maiores produtividades foram obtidas no consórcio irrigado (Tabela 2). No entanto, na última safra, a macadâmia solteira irrigada apresentou maior produtividade, provavelmente porque as podas realizadas nas nogueiras do consórcio impediram maiores produções. No somatório das cinco safras, a consorciação aumentou a produtividade da nogueira-macadâmia em $51 \%$, em condição de sequeiro, e em $27 \%$ no

Tabela 2. Produtividades de grãos beneficiados de cafeeiro arábica (Coffea arabica), em sacas por hectare, e de amêndoas de nogueira-macadâmia (Macadamia integrifolia), em kg ha-1, bem como índice de equivalência da área (IEA), nas cinco primeiras safras, em cultivo solteiro e consorciado, com e sem irrigação por gotejamento, de 2008 a $2013^{(1)}$.

\begin{tabular}{|c|c|c|c|c|c|c|c|c|c|c|c|c|c|c|}
\hline \multirow[t]{2}{*}{ Tratamento } & \multicolumn{2}{|c|}{2008} & \multicolumn{2}{|c|}{2009} & \multicolumn{2}{|c|}{2010} & \multicolumn{2}{|c|}{2011} & \multicolumn{2}{|c|}{2012} & \multicolumn{2}{|c|}{2013} & \multicolumn{2}{|c|}{ Total } \\
\hline & Café & Mac. $^{(2)}$ & Café & Mac. & Café & Mac. & Café & Mac. & Café & Mac. & Café & Mac. & Café & Mac. \\
\hline & \multicolumn{14}{|c|}{ Produtividade } \\
\hline Café solteiro sequeiro & $10,1 b$ & - & $31,5 b$ & - & $65,5 b$ & - & $21,1 \mathrm{a}$ & - & $24,5 \mathrm{~d}$ & - & - & - & $153 c$ & - \\
\hline Café solteiro irrigado & $26,1 \mathrm{a}$ & - & $47,8 \mathrm{a}$ & - & $82,8 \mathrm{a}$ & - & $15,3 b$ & - & $90,9 \mathrm{a}$ & - & - & - & $263 \mathrm{a}$ & - \\
\hline Consórcio sequeiro & $10,6 b$ & - & $30,9 b$ & $9,4 b$ & $75,1 \mathrm{ab}$ & $65,4 \mathrm{c}$ & $20,3 a$ & $154,8 b c$ & $31,8 \mathrm{c}$ & $178,4 b$ & - & $333,3 \mathrm{c}$ & $169 b$ & $741 \mathrm{c}$ \\
\hline Consórcio irrigado & $23,7 \mathrm{a}$ & - & $48,3 \mathrm{a}$ & $40,3 \mathrm{a}$ & $83,6 a$ & $140,3 \mathrm{a}$ & $17,3 \mathrm{ab}$ & $535,7 \mathrm{a}$ & $79,7 b$ & $361,0 \mathrm{a}$ & - & $648,5 b$ & $253 a$ & $1.726 \mathrm{a}$ \\
\hline Macadâmia solteira sequeiro & - & - & - & $2,1 \mathrm{c}$ & - & $13,8 \mathrm{~d}$ & - & $79,3 \mathrm{c}$ & - & $139,4 b$ & - & $256,6 \mathrm{c}$ & - & $492 d$ \\
\hline Macadâmia solteira irrigada & - & - & - & $13,1 \mathrm{~b}$ & - & $88,8 \mathrm{~b}$ & - & $197,4 \mathrm{~b}$ & - & $301,3 \mathrm{a}$ & - & $756,4 \mathrm{a}$ & - & $1.357 \mathrm{~b}$ \\
\hline \multirow[t]{2}{*}{$\mathrm{CV}(\%)$} & 15,6 & - & 15,2 & 32,2 & 11,1 & 22,3 & 21,5 & 28,2 & 6,1 & 30,3 & - & 16,3 & 5,7 & 9,9 \\
\hline & \multicolumn{14}{|c|}{ Índice de equivalência da área (IEA) } \\
\hline Café solteiro irrigado & \multicolumn{2}{|c|}{2,58} & \multicolumn{2}{|c|}{1,52} & \multicolumn{2}{|c|}{1,26} & \multicolumn{2}{|c|}{0,73} & \multicolumn{2}{|c|}{3,71} & \multicolumn{2}{|r|}{ - } & \multicolumn{2}{|c|}{1,72} \\
\hline Consórcio sequeiro & \multicolumn{2}{|c|}{1,05} & \multicolumn{2}{|c|}{5,46} & \multicolumn{2}{|c|}{5,89} & \multicolumn{2}{|c|}{2,91} & \multicolumn{2}{|c|}{2,64} & \multicolumn{2}{|c|}{1,30} & \multicolumn{2}{|c|}{2,63} \\
\hline Consórcio irrigado & \multicolumn{2}{|c|}{2,35} & \multicolumn{2}{|c|}{20,72} & \multicolumn{2}{|c|}{11,44} & \multicolumn{2}{|c|}{7,58} & \multicolumn{2}{|c|}{5,84} & \multicolumn{2}{|c|}{2,53} & \multicolumn{2}{|c|}{5,16} \\
\hline Macadâmia solteira irrigada & \multicolumn{2}{|c|}{ - } & \multicolumn{2}{|c|}{6,19} & & 43 & & 49 & & 16 & & ,95 & & 76 \\
\hline
\end{tabular}

${ }^{(1)}$ Médias seguidas de letras iguais, nas colunas, para a produtividade, não diferem entre si, pelo teste de Tukey, a $5 \%$ de probabilidade. ${ }^{(2)}$ Mac., macadâmia. 
cultivo irrigado, quando comparada a do monocultivo. Perdoná et al. (2012a) observaram que essa nogueira, em consórcio com cafeeiros, aproveita as condições de fertilidade e sombreamento do solo, para um maior desenvolvimento do seu sistema radicular, e consegue atingir maior crescimento e produção.

Independentemente da consorciação ou não com o cafeeiro, o uso da irrigação incrementou significativamente a produtividade da nogueiramacadâmia em todos os anos (Tabela 2). No total das cinco safras, houve aumento da produtividade de amêndoas em 130\% das nogueiras consorciadas e em $176 \%$ das nogueiras solteiras, com a irrigação. Segundo Stephenson et al. (2003), mesmo curtos períodos de estresse hídrico, em qualquer uma das fases reprodutivas (iniciação e desenvolvimento floral e expansão, e maturação dos frutos), reduz a produtividade da nogueira-macadâmia. Isso pode explicar os resultados obtidos, uma vez que, entre agosto e setembro da maioria dos anos avaliados, nos estádios de florescimento e início do crescimento dos frutos (Tabela 1), houve reduzida precipitação pluvial, o que provavelmente causou estresse por seca às plantas de macadâmia nos cultivos não irrigados.

O IEA dá a dimensão da eficiência no uso da terra proporcionada por um determinado tratamento e permite, inclusive, a soma do desempenho de diferentes culturas que ocupam a mesma área. No presente trabalho, tanto no cafeeiro quanto na nogueira-macadâmia, solteiros, a irrigação melhorou o uso da terra, com IEA de 1,72 e 2,76, respectivamente, tendo-se considerado a produtividade total de cinco anos (Tabela 2). Em condição de sequeiro, a consorciação entre as duas culturas melhorou a eficiência de uso da terra (IEA=2,63), em comparação aos monocultivos. Embora o IEA tenha aumentado consideravelmente com o uso da irrigação nas duas culturas solteiras e com a consorciação em condição de sequeiro, o consórcio irrigado foi o tratamento que proporcionou o melhor uso da terra (Tabela 2). Quanto à produtividade total dos cinco anos, o consórcio irrigado apresentou IEA de 5,16 . Com esse resultado, pode-se inferir que, para os monocultivos em condição de sequeiro produzirem a mesma quantidade de grãos de café beneficiados ou de amêndoas de nogueira-macadâmia que a de um hectare do consórcio irrigado, seriam necessários 1,65 ha de cafeeiro e 3,51 ha de nogueira-macadâmia cultivados em sequeiro, o que totalizaria 5,16 ha. Portanto, nesse caso, os monocultivos em condição de sequeiro exigiriam cinco vezes mais área do que o cultivo em consórcio irrigado. Esses valores são fundamentais para o sucesso do empreendimento, principalmente quando se trata de áreas com elevados valores para o preço da terra, como no Estado de São Paulo. Além disso, o melhor aproveitamento no uso da terra diminui os processos erosivos, preserva os recursos naturais, diminui a expansão da agricultura sobre as florestas e possibilita a sustentabilidade dos cultivos em regiões tradicionais, $o$ que impede sua migração para outras regiões. Contudo, os valores de IEA do consócio irrigado foram maiores nos primeiros anos (2009 a 2011), o que mostra que, com o passar dos anos, a consorciação apresentou menor vantagem sobre os cultivos solteiros, especialmente sob irrigação (Tabela 2).

Os menores custos de implantação foram observados nos tratamentos de sequeiro, mais especificamente na cultura da nogueira-macadâmia solteira sequeiro, seguida do cafeeiro solteiro sequeiro e do consórcio sequeiro (Tabela 3). O maior custo de implantação do consórcio decorreu, principalmente, da aquisição de mudas de ambas as culturas para uma mesma área. O maior custo de implantação do cafeeiro solteiro, em relação à nogueira-macadâmia solteira, pode ser explicado pela necessidade de aquisição de maior quantidade de mudas e de realização de sulcação e fertilização, consequentes do espaçamento mais estreito utilizado na cultura do cafeeiro. A irrigação por gotejamento foi a tecnologia que mais aumentou o CTP de maneira geral, em todos os anos de estudo (Tabela 3). Ao se analisar separadamente o custo de implantação de cada tratamento, constatou-se que a adoção da irrigação incrementou o custo em $66 \%$ no consórcio, $84 \%$ no café solteiro e em $121 \%$ na macadâmia solteira. Esses resultados são justificados, já que a instalação do sistema de irrigação por gotejamento exige altos investimentos em obras e equipamentos (Silva et al., 2003). Destaca-se, também, que o uso da irrigação aumentou o CTP em todos os anos, o que está relacionado a gastos com energia elétrica, bem como com operação e manutenção do sistema de irrigação. De acordo com Silva et al. (2003) e Oliveira et al. (2010), a irrigação aumentou o CTP, enquanto o uso da irrigação por gotejamento reduziu o custo por saca de café produzida, ao aumentar a produtividade. 
Tabela 3. Custo de produção, receita bruta e resultados econômicos acumulados ( $\left.\mathrm{R} \$ \mathrm{ha}^{-1}\right)$, da implantação até a quinta safra, do cafeeiro arábica (Coffea arabica) e da nogueira-macadâmia (Macadamia integrifolia), em cultivo solteiro e consorciado, com e sem irrigação por gotejamento, relativamente a três preços de venda do café.

\begin{tabular}{|c|c|c|c|c|c|c|c|c|}
\hline $\begin{array}{l}\text { Custos/ } \\
\text { Receitas }^{(1)}\end{array}$ & 2006 & 2007 & 2008 & 2009 & 2010 & 2011 & 2012 & 2013 \\
\hline & & & & Café sol & sequeiro & & & \\
\hline \multirow[t]{2}{*}{ СТP } & $9.372,79$ & $3.178,87$ & $5.386,72$ & $8.798,26$ & $14.078,44$ & $6.940,76$ & $10.098,79$ & - \\
\hline & \multicolumn{8}{|c|}{ Preço de venda do café : $\mathrm{R} \$ 307,00$ por saca } \\
\hline $\mathrm{RB}$ & & & $3.085,35$ & $9.658,22$ & $20.105,43$ & $6.486,91$ & $7.534,76$ & \\
\hline \multirow[t]{2}{*}{ REA } & $-9.372,79$ & $-12.551,66$ & $-14.853,04$ & $-13.993,08$ & $-7.966,09$ & $-8.419,94$ & $-10.983,97$ & $-10.983,97$ \\
\hline & \multicolumn{8}{|c|}{ Preço de venda do café : $R \$ 357,40$ por saca } \\
\hline $\mathrm{RB}$ & & & $3.591,87$ & $11.243,80$ & $23.406,13$ & $7.551,86$ & $8.771,74$ & \\
\hline \multirow[t]{2}{*}{ REA } & $-9.372,79$ & $-12.551,66$ & $-14.346,52$ & $-11.900,98$ & $-2.573,29$ & $-1.962,19$ & $-3.289,24$ & $-3.289,24$ \\
\hline & \multicolumn{8}{|c|}{ Preço de venda do café - $\mathrm{R} \$ 405,41$ por saca } \\
\hline $\mathrm{RB}$ & & & $4.074,37$ & $12.754,20$ & $26.550,30$ & $8.566,31$ & $9.950,05$ & \\
\hline \multirow[t]{2}{*}{ REA } & $-9.372,79$ & $-12.551,66$ & $-13.864,02$ & $-9.908,08$ & $2.563,78$ & $4.189,33$ & $4.040,60$ & $4.040,60$ \\
\hline & \multicolumn{8}{|c|}{ Café solteiro irrigado } \\
\hline \multirow[t]{2}{*}{ СТP } & $17.192,03$ & $3.442,57$ & $6.930,64$ & $10.682,96$ & $16.692,84$ & $6.780,20$ & $17.489,54$ & - \\
\hline & \multicolumn{8}{|c|}{ Preço de venda do café : $R \$ 307,00$ por saca } \\
\hline $\mathrm{RB}$ & & & $8.009,63$ & $14.659,25$ & $25.428,81$ & $4.697,10$ & $27.892,54$ & \\
\hline \multirow[t]{2}{*}{ REA } & $-17.192,03$ & $-20.634,60$ & $-19.555,61$ & $-15.579,32$ & $-6.843,36$ & $-8.926,45$ & $1.476,55$ & $1.476,55$ \\
\hline & \multicolumn{8}{|c|}{ Preço de venda do café : $\mathrm{R} \$ 357,40$ por saca } \\
\hline $\mathrm{RB}$ & & & $9.324,57$ & $17.065,85$ & $29.603,44$ & $5.468,22$ & $32.471,65$ & \\
\hline \multirow[t]{2}{*}{ REA } & $-17.192,03$ & $-20.634,60$ & $-18.240,68$ & $-11.857,79$ & $1.052,81$ & $-259,16$ & $14.722,94$ & $14.722,94$ \\
\hline & \multicolumn{8}{|c|}{ Preço de venda do café : $\mathrm{R} \$ 405,41$ por saca } \\
\hline $\mathrm{RB}$ & & & $10.577,15$ & $19.358,33$ & $33.580,11$ & $6.202,77$ & $36.833,60$ & \\
\hline \multirow[t]{2}{*}{ REA } & $-17.192,03$ & $-20.634,60$ & $-16.988,10$ & $-8.312,73$ & $8.574,54$ & $7.997,12$ & $27.341,18$ & $27.341,18$ \\
\hline & \multicolumn{8}{|c|}{ Consórcio sequeiro } \\
\hline \multirow[t]{2}{*}{ CTP } & $11.666,57$ & $3.327,42$ & $5.698,09$ & $9.277,90$ & $15.102,36$ & $7.976,51$ & $11.473,07$ & $1.528,46$ \\
\hline & \multicolumn{8}{|c|}{ Preço de venda do café : R\$ 307,00 por saca } \\
\hline $\mathrm{RB}$ & & & $3.241,92$ & $9.654,28$ & $24.204,02$ & $8.943,77$ & $13.047,77$ & $5.865,16$ \\
\hline REA & $-11.666,57$ & $-14.993,99$ & $-17.424,17$ & $-16.971,71$ & $-7.685,22$ & $-6.668,08$ & $-5.015,13$ & $-678,42$ \\
\hline & & & & de venda do & $: \mathrm{R} \$ 357,40 \mathrm{p}$ & & & \\
\hline $\mathrm{RB}$ & & & $3.774,14$ & $11.212,15$ & $27.988,56$ & $9.964,88$ & $14.649,99$ & $5.865,16$ \\
\hline REA & $-11.666,57$ & $-14.993,99$ & $-16.905,26$ & $-14.933,90$ & $-1.957,53$ & 55,17 & $3.270,26$ & $7.606,97$ \\
\hline & & & & de venda do & : $\mathrm{R} \$ 405,41 \mathrm{p}$ & & & \\
\hline $\mathrm{RB}$ & & & $4.281,13$ & $12.696,14$ & $31.593,63$ & $10.937,56$ & $16.176,23$ & $5.865,16$ \\
\hline REA & $-11.666,57$ & $-14.993,99$ & $-16.410,96$ & $-12.992,72$ & $3.498,54$ & $6.459,59$ & $11.162,75$ & $15.499,46$ \\
\hline & & & & Consó & irrigado & & & \\
\hline СТP & $19.349,27$ & $3.591,12$ & $7.162,42$ & $11.305,45$ & $17.749,64$ & $9.299,59$ & $18.998,60$ & $2.691,05$ \\
\hline & & & & de venda do & : $\mathrm{R} \$ 307,00 \mathrm{p}$ & & & \\
\hline $\mathrm{RB}$ & & & $7.278,97$ & $15.521,33$ & $28.133,95$ & $14.736,00$ & $30.812,47$ & $11.413,00$ \\
\hline REA & $-19.349,27$ & $-22.940,39$ & $-22.823,84$ & $-18.607,97$ & $-8.223,66$ & $-2.787,25$ & $9.026,61$ & $17.748,56$ \\
\hline & & & & de venda do & $: \mathrm{R} \$ 357,40 \mathrm{p}$ & & & \\
\hline $\mathrm{RB}$ & & & $8.473,95$ & $17.953,13$ & $32.347,39$ & $15.607,41$ & $34.827,83$ & $11.413,00$ \\
\hline REA & $-19.349,27$ & $-22.940,39$ & $-21.628,86$ & $-14.981,18$ & $-383,43$ & $5.924,39$ & $21.753,62$ & $30.475,57$ \\
\hline & & & & de venda do & : $\mathrm{R} \$ 405,41 \mathrm{p}$ & & & \\
\hline $\mathrm{RB}$ & & & $9.612,27$ & $20.269,61$ & $36.361,03$ & $16.437,51$ & $38.652,79$ & $11.413,00$ \\
\hline REA & $-19.349,27$ & $-22.940,39$ & $-20.490,54$ & $-11.526,38$ & $7.085,00$ & $14.222,92$ & $33.877,11$ & $42.599,06$ \\
\hline & & & & gueira-macad & a solteira sequ & & & \\
\hline СТP & $4.626,34$ & $1.450,70$ & $1.707,70$ & $1.688,21$ & $2.007,75$ & $2.116,07$ & $2.565,64$ & $1.773,51$ \\
\hline $\mathrm{RB}$ & & & 0,00 & 37,49 & 243,41 & $1.396,03$ & $2.454,14$ & $4.515,76$ \\
\hline REA & $-4.626,34$ & $-6.077,04$ & $-7.784,74$ & $-9.435,46$ & $-11.199,80$ & $-11.919,83$ & $-12.031,33$ & $-9.289,08$ \\
\hline & & & & gueira-macac & a solteira irri & & & \\
\hline СТP & $9.924,95$ & $1.692,99$ & $2.006,79$ & $2.134,87$ & $2.723,12$ & $2.443,17$ & $3.471,00$ & $3.467,06$ \\
\hline $\mathrm{RB}$ & & & & 229,68 & $1.562,88$ & $3.474,24$ & $5.302,88$ & $13.312,89$ \\
\hline REA & $-9.924,95$ & $-11.617,94$ & $-13.624,73$ & $-15.529,92$ & $-16.690,16$ & $-15.659,09$ & $-13.827,21$ & $-3.981,38$ \\
\hline
\end{tabular}

${ }^{(1)} \mathrm{CTP}$, custo total de produção; RB, receita bruta; REA, resultados econômicos acumulados. 
O preço do café normalmente sofre consideráveis variações dentro e entre os anos, uma vez que o desempenho econômico do empreendimento está diretamente relacionado ao preço de venda do produto. Assim, preços diferentes para o café podem proporcionar diferentes resultados quanto à rentabilidade do sistema de produção (Oliveira et al., 2010). Portanto, em um cenário no qual o preço do café fosse o mínimo (R\$ 307,00 por saca) estabelecido pelo Governo Federal (Acompanhamento da Safra Brasileira, 2014), no cultivo de café solteiro sequeiro, sete anos após a implantação da lavoura e depois da colheita da quinta safra, o produtor teria um prejuízo acumulado de R\$ 10.983,97 ha ${ }^{-1}$ (Tabela 3 e Figura 2A). Embora o uso isolado da consorciação e da irrigação tenha proporcionado resultados econômicos mais favoráveis em razão dos incrementos de produtividade da cultura do cafeeiro (café solteiro irrigado) e das receitas provenientes da venda da noz da nogueira-macadâmia (consórcio sequeiro), a associação dessas tecnologias, ou seja, o consórcio irrigado, permitiria a obtenção do melhor resultado, de $\mathrm{R} \$ 17.748,56 \mathrm{ha}^{-1}$, no período avaliado.

Para o preço do café de $\mathrm{R} \$ 357,40$ por saca, os resultados econômicos ainda seriam negativos para $\mathrm{o}$ cultivo de cafeeiro solteiro em condição de sequeiro, no período estudado, mas já seriam positivos para o consórcio sequeiro ( $\left.\mathrm{R} \$ 7.606,97 \mathrm{ha}^{-1}\right)$ e, principalmente, para o café solteiro irrigado ( $\left.\mathrm{R} \$ 14.722,94 \mathrm{ha}^{-1}\right)$ (Tabela 3 e Figura 2B). O uso de qualquer dessas tecnologias separadamente anteciparia o retorno do investimento. Entretanto, o resultado econômico mais favorável seria obtido no consórcio irrigado $(\mathrm{R} \$$ $\left.30.475,57 \mathrm{ha}^{-1}\right)$.

O preço da saca de café de $\mathrm{R} \$ 405,41$ resultaria em retorno do capital investido, a partir da terceira safra de café, em todos os tratamentos nos quais o cafeeiro fizesse parte do sistema de cultivo (Tabela $3 \mathrm{e}$ Figura 2C). Nesse nível de preço do café, os sistemas irrigados, que tiveram maiores produtividades (Tabela 2), diferenciaram-se dos tratamentos em condição de sequeiro, após cinco safras. Porém, com os incrementos de produtividade de ambas as culturas e das receitas advindas da macadâmia, os melhores resultados econômicos seriam obtidos no consórcio irrigado ( $\mathrm{R} \$ 42.599,06 \mathrm{ha}^{-1}$ ).

No caso da nogueira-macadâmia solteira, apesar de apresentar CTP maiores, o cultivo irrigado, proporcionou melhor resultado econômico que o cultivo em condição de sequeiro, em decorrência de sua maior produtividade (Tabela 2). Pimentel et al. (2007) estimaram que o retorno do investimento aconteceria em 12 anos, no cultivo da nogueira-macadâmia solteira não irrigada, no Estado de São Paulo. No presente trabalho, após a quinta safra, isto é, oito anos após o plantio, a nogueira-macadâmia solteira em condição de sequeiro ainda acumulava um prejuízo de $\mathrm{R} \$$ 9.943,51 ha ${ }^{-1}$. Dessa forma, os resultados obtidos no presente trabalho são indicativos de que o uso da irrigação e/ou da consorciação com café arábica são alternativas que melhoram o desempenho técnico e econômico da nogueira-macadâmia, o que reduz significativamente o período de retorno do investimento e pode permitir a expansão mais rápida de seu cultivo no estado.

Quando se considera os três cenários de preços de venda do café, somente o consórcio irrigado gerou um VPL positivo em todas as situações (Tabela 4). Desse modo, os tratamentos café solteiro sequeiro, consórcio café-nogueira-macadâmia sequeiro, nogueira-macadâmia solteira sequeiro e nogueira-macadâmia solteira irrigada foram inviáveis com os valores mínimos do preço do café, durante o período de estudo. No cenário mais otimista, com preços de café de $\mathrm{R} \$ 405,41$ por saca, todos os tratamentos com café apresentaram valores de VPL positivos, e somente o café solteiro em condições de sequeiro apresentou valores negativos para os preços intermediários de venda de café.

Com relação ao indicador TIR, o consórcio irrigado também remunerou o capital investido nos três cenários, em 12,2, 19,7 e 26,1\%, quando se considera os preços de venda do café, respectivamente, de $\mathrm{R} \$ 307,00, \mathrm{R} \$ 357,40$ e $\mathrm{R} \$ 405,41$ por saca (Tabela 4). Similarmente, o café solteiro irrigado apresentou TIR positiva nas três situações, tendo chegado a $22,8 \%$ na melhor delas. No entanto, o café solteiro sequeiro apresentou TIR positiva somente no cenário de maior preço do café, e o consórcio sequeiro apresentou TIR com valor negativo no caso de menor preço do café.

Os cultivos de nogueira-macadâmia com ou sem irrigação apresentaram VPL negativo, o que indica a não remuneração do capital nesses tratamentos, no período, quando se considera uma taxa de juros de 6\% ao ano (Tabela 4). Resultados semelhantes foram obtidos por Pimentel et al. (2007), para o cultivo de nogueira-macadâmia solteira em condições de sequeiro, com resultado negativo até o décimo ano de 


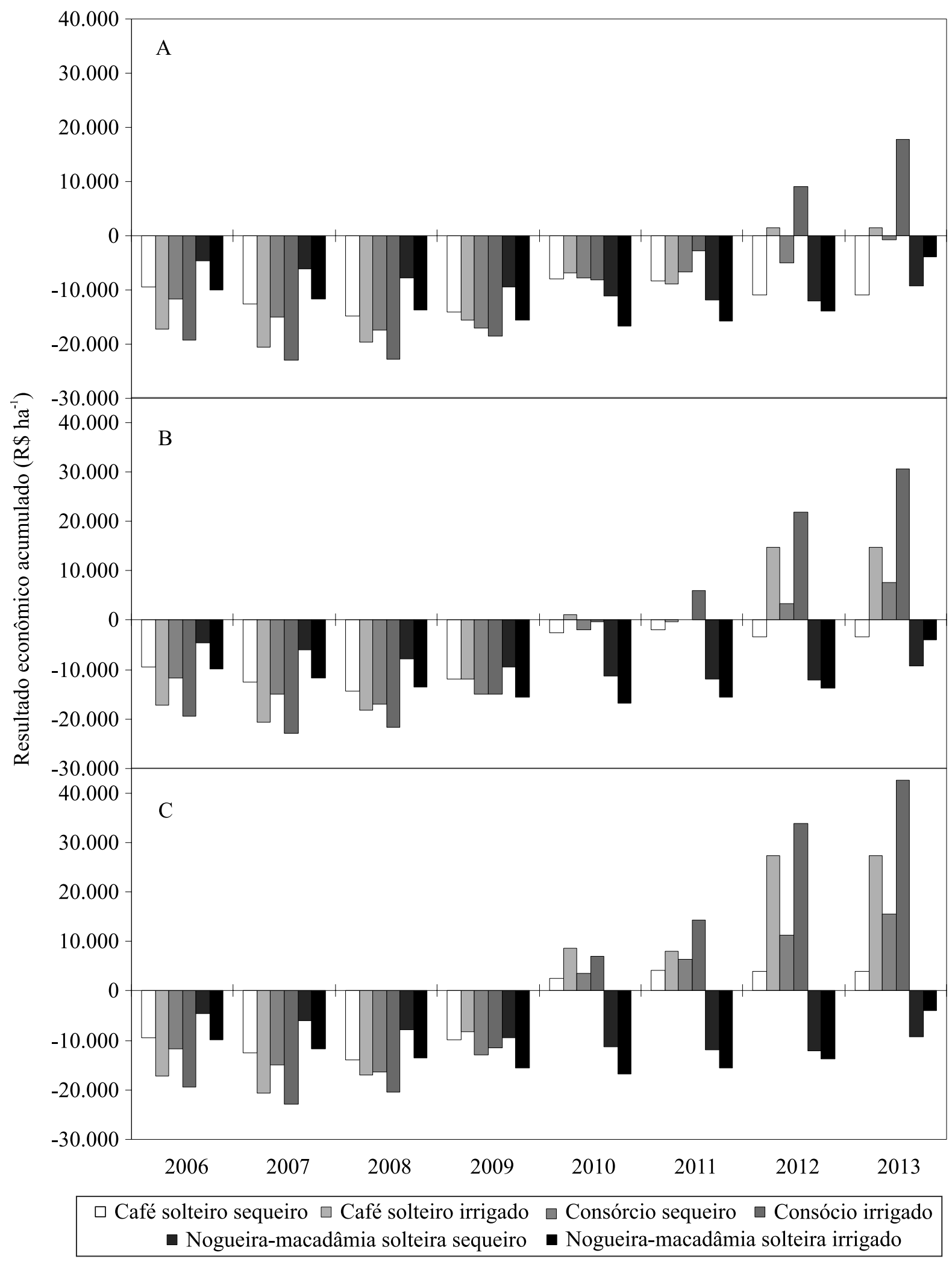

Figura 2. Resultados econômicos acumulados, da implantação até a quinta safra, do café arábica (Coffea arabica) e da nogueira-macadâmia (Macadamia integrifolia), em cultivo solteiro e consorciado, com e sem irrigação por gotejamento, de 2006 a 2013, relativamente a três preços de venda do café: A, $\mathrm{R} \$ 307,00$ por saca; $B, \mathrm{R} \$ 357,40$ por saca; $\mathrm{C}, \mathrm{R} \$ 405,41$ por saca. 
Tabela 4. Indicadores de avaliação da viabilidade econômica do café arábica (Coffea arabica) e da nogueira-macadâmia (Macadamia integrifolia), em cultivo solteiro e consorciado, com e sem irrigação por gotejamento, relativamente a três preços de venda do café.

\begin{tabular}{lcc}
\hline Tratamento & VPL $(\mathrm{R} \$)$ & TIR $(\%)$ \\
\hline & Preço de venda do café : R $\$ 307,00$ por saca \\
Café solteiro sequeiro & $-10.444,01$ & - \\
Café solteiro irrigado & $-3.249,12$ & 1,6 \\
Consórcio sequeiro & $-4.172,97$ & $-0,9$ \\
Consórcio irrigado & $6.908,48$ & 12,2 \\
\hline & Preço de venda do café : R $\$ 357,40$ por saca \\
Café solteiro sequeiro & $-4.722,91$ & $-8,1$ \\
Café solteiro irrigado & $6.469,68$ & 13,6 \\
Consórcio sequeiro & $1.963,87$ & 9,0 \\
Consórcio irrigado & $16.271,31$ & 19,7 \\
\hline & Preço de venda do café : R $\$ 405,41$ por saca \\
Café solteiro sequeiro & 726,89 & 7,7 \\
Café solteiro irrigado & $15.727,60$ & 22,8 \\
Consórcio sequeiro & $7.809,70$ & 17,0 \\
Consórcio irrigado & $25.190,16$ & 26,1 \\
\hline Nogueira-macadâmia SS & $-8.576,58$ & - \\
Nogueira-macadâmia SI & $-6.808,38$ & $-0,1$ \\
\hline VPL, valor presente líquido. TIR, taxa interna de retorno. SS, solteira se- \\
queiro. SI, solteira irrigada.
\end{tabular}

cultivo. No presente trabalho, a TIR foi próxima de zero $(-0,1 \%)$ para o cultivo da nogueira-macadâmia solteira irrigada, o que mostra maior viabilidade em relação à condição de sequeiro.

Embora a principal forma de cultivo do cafeeiro e da nogueira-macadâmia no Estado de São Paulo seja o monocultivo sem irrigação, os resultados obtidos são indicativos de que, pelo menos até o sétimo ano após o plantio, esse é o sistema de cultivo de menor eficiência técnica e econômica, entre os tratamentos testados (Tabelas 2, 3 e 4 e Figura 2). O uso da consorciação e da irrigação permite melhor aproveitamento do uso da terra, diminui o período de retorno do investimento, amplia a renda e a viabilidade financeira desses cultivos no Estado de São Paulo e apresenta potencial para evitar a migração dessas culturas e as perdas econômicas, sociais e ambientais.

\section{Conclusões}

1. A irrigação por gotejamento e o cultivo consorciado aumentam a produtividade do cafeeiro arábica (Coffea arabica) e da nogueira-macadâmia (Macadamia integrifolia), em comparação aos monocultivos em condição de sequeiro, e, em geral, proporcionam a mesma produtividade dos monocultivos irrigados de café, além de produtividade superior à dos monocultivos irrigados de macadâmia.

2. A associação da consorciação de cafeeiro arábica e nogueira-macadâmia com a irrigação aumenta a eficiência do uso da terra em cinco vezes, em relação às médias das culturas solteiras em condição de sequeiro.

3. O cultivo consorciado de cafeeiro arábica e nogueira-macadâmia sob irrigação proporciona maior rentabilidade e mais rápido retorno do investimento, $\mathrm{o}$ que o torna uma alternativa viável, especialmente em períodos de menores preços do café.

\section{Agradecimentos}

À Fundação de Amparo à Pesquisa do Estado de São Paulo (Fapesp), processo no 2011/17940-0, pelo apoio financeiro; e ao Conselho Nacional de Desenvolvimento Científico e Tecnológico (CNPq), pela concessão de bolsa de produtividade em pesquisa.

\section{Referências}

ACOMPANHAMENTO DA SAFRA BRASILEIRA: Café - Safra 2014 - Primeiro Levantamento. Brasília: Conab, v.1, n.1, jan. 2014. 58p. Disponível em: <http://www.conab.gov.br/OlalaCMS/ uploads/arquivos/14_09_16_08_47_43_boletim_setembro_2014. pdf>. Acesso em: 18 mar. 2014.

APARECIDO, L.E.deO.; ROLIM, G.de S.; SOUZA, P.S.de.Épocas de florescimento e colheita da nogueira-macadâmia para áreas cafeícolas da região Sudeste. Revista Brasileira de Fruticultura, v.36, p.170-178, 2014. DOI: 10.1590/0100-2945-288/13.

ARÊDES, A.F. de; PEREIRA, M.W.G.; SANTOS, M.L. dos. A irrigação do cafezal como alternativa econômica ao produtor. Acta Scientiarum. Agronomy, v.32, p.193-200, 2010. DOI: 10.4025/actasciagron.v32i2.1624.

ARRUDA, F.B.; GRANDE, M.A. Fator de resposta da produção de cafeeiro ao déficit hídrico em Campinas. Bragantia, v.62, p.139-145, 2003. DOI: 10.1590/S0006-87052003000100017.

ASSAD, E.D.; PINTO, H.S.; ZULLO JUNIOR, J.; ÁVILA, A.M.H. de. Impacto das mudanças climáticas no zoneamento agroclimático do café no Brasil. Pesquisa Agropecuária Brasileira, v.39, p.1057-1064, 2004. DOI: 10.1590/S0100-204X2004001100001.

CAFÉ. In: AGRIANUAL 2011: anuário da agricultura brasileira. São Paulo: FNP, 2011. p.202-205.

CENTRO DE PESQUISAS METEOROLÓGICAS E CLIMÁTICAS APLICADAS À AGRICULTURA. Clima dos municípios paulistas: Dois Córregos. 2014. Disponível em: $<$ http:// www.cpa.unicamp.br/outras-informacoes/clima_muni_158.html $>$. Acesso em: 6 nov. 2014. 
CHUNG, K.H.; SHIN, K.O.; HWANG, H.J.; CHOI, K.S. Chemical composition of nuts and seeds sold in Korea. Nutrition Research and Practice, v.7, p.82-88, 2013. DOI: 10.4162/nrp.2013.7.2.82.

COOPERATIVA REGIONAL DOS CAFEICULTORES EM GUAXUPÉ. Preço histórico do café. Guaxupé: Cooxupé, 2013. Disponível em: <http://portalweb.cooxupe.com.br:8080/portal/ precohistoricocafe.jsp>. Acesso em: 5 fev. 2013.

DAMATTA, F.M. Ecophysiological constraints on the production of shaded and unshaded coffee: a review. Field Crops Research, v.86, p.99-114, 2004. DOI: 10.1016/j.fcr.2003.09.001

DAMATTA, F.M.; RONCHI, C.P.; MAESTRI, M.; BARROS, R.S. Ecophysiology of coffee growth and production. Brazilian Journal of Plant Physiology, v.19, p.485-510, 2007. DOI: 10.1590/S1677-04202007000400014.

DECONTO, J.G. (Coord.). Aquecimento global e a nova geografia da produção agrícola no Brasil. [Brasília]: Embrapa; [Campinas]: Unicamp, 2008. 82p.

ELEVITCH, C.; IDOL, T.; FRIDAY, J.B.; LEPCZYK, C.; SMITH, V.E.; NELSON, S.C. Shade-grown coffee in Hawai'i: results of a twelve farm study in Kona. Holualoa: Permanent Agriculture Resources, 2009. 22p. Available at: <http://agroforestry.net/caf $>$. Accessed on: 06 Nov. 2014.

INSTITUTO DE ECONOMIA AGRÍCOLA. Banco de dados. Disponível em: <http://www.iea.sp.gov.br/out/bancodedados. html >. Acesso em: 19 mar. 2014.

NICOLELI, M.; MOLLER, H.D. Análise da competitividade dos custos do café orgânico sombreado irrigado. Custos e Agronegócio, v.2, p.29-44, 2006.

OLIVEIRA, E.L. de; FARIA, M.A. de; REIS, R.P.; SILVA, M. de L.O. e. Manejo e viabilidade econômica da irrigação por gotejamento na cultura do cafeeiro Acaiá consideração seis safras. Engenharia Agrícola, v.30, p.887-896, 2010. DOI: 10.1590/ S0100-69162010000500011.

PERDONÁ, M.J.; MARTINS, A.M.; SUGUINO, E.; SORATTO, R.P. Crescimento e produtividade de nogueira-macadâmia em consórcio com cafeeiro arábica irrigado. Pesquisa Agropecuária Brasileira, v.47, p.1613-1620, 2012a. DOI: 10.1590/ S0100-204X2012001100008.

PERDONÁ, M.J.; SORATTO, R.P.; MARTINS, A.M.; SUGUINO, E.; MANCUSO, M.A.C. Irrigação e certificação da cafeicultura do Centro-Oeste de São Paulo. Bragantia, v.71, p. 377-384, 2012 b. DOI: $10.1590 / \mathrm{S} 0006-87052012005000034$.

PEZZOPANE, J.R.M.; MARSETTI, M.M.S.; SOUZA, J.M. de; PEZZOPANE, J.E.M. Condições microclimáticas em cultivo de café conilon a pleno sol e arborizado com nogueira macadâmia. Ciência Rural, v.40, p.1257-1263, 2010. DOI: 10.1590/ S0103-84782010005000098.

PIMENTEL, L.D.; SANTOS, C.E.M. dos; WAGNER JÚNIOR, A.; SILVA, V.A.; BRUCKNER, C.H. Estudo de viabilidade econômica na cultura da noz-macadâmia no Brasil. Revista Brasileira de Fruticultura, v.29, p.500-507, 2007. DOI: 10.1590/ S0100-29452007000300018.
QUAGGIO, J.A.; RAIJ, B. van; PIZA JUNIOR, C.T. Frutíferas. Frutas de clima temperado: III. Caqui, maçã, macadâmia, pecã e pêra. In: RAIJ, B. van; CANTARELLA, H.; QUAGGIO, J.A.; FURLANI, A.M.C. (Ed.). Recomendações de adubação e calagem para o Estado de São Paulo. 2.ed. rev. atual. Campinas: Instituto Agronômico: Fundag, 1997. p.121-153. (IAC. Boletim técnico, 100).

RAIJ, B. van; CANTARELLA, H.; QUAGGIO, A.J. Estimulantes: café. In: RAIJ, B. van; CANTARELLA, H.; QUAGGIO, J.A.; FURLANI, A.M.C. (Ed.). Recomendações de adubação e calagem para o Estado de São Paulo. 2.ed. rev. atual. Campinas: Instituto Agronômico: Fundag, 1997. p.97-101. (IAC. Boletim técnico, 100).

SANTOS, H.G. dos; JACOMINE, P.K.T.; ANJOS, L.H.C. dos; OLIVEIRA, V.A. de; OLIVEIRA, J.B. de; COELHO, M.R.; LUMBRERAS, J.F.; CUNHA, T.J.F. (Ed.). Sistema brasileiro de classificação de solos. 2.ed. Rio de Janeiro: Embrapa Solos, 2006. $306 \mathrm{p}$.

SILVA, A.L. da; FARIA, M.A. de; REIS, R.P. Viabilidade técnico-econômica do uso do sistema de irrigação por gotejamento na cultura do cafeeiro. Revista Brasileira de Engenharia Agrícola e Ambiental, v.7, p.37-44, 2003. DOI: 10.1590/ S1415-43662003000100007.

SILVA, V. de C.; PERDONÁ, M.J.; SORATTO, R.P.; NEGRISOLI, E. Ocorrência de plantas daninhas em cultivo consorciado de café e nogueira-macadâmia. Pesquisa Agropecuária Tropical, v.43, p.441-449, 2013. DOI: 10.1590/S1983-40632013000400013.

SILVA, V.A.; LIMA, L.A.; ANDRADE, F.T.; FERREIRA, E.A.; SOUZA JÚNIOR, E.A. de; COLARES, M.F.B.; MOREIRA, L.L.Q. Sistemas intercalares com abacaxizeiro como alternativa de renda durante a formação de cafezais irrigados. Pesquisa Agropecuária Brasileira, v.47, p.1471-1479, 2012. DOI: 10.1590/S0100-204X2012001000009.

STEIMAN, S.; IDOL, T.; BITTENBENDERA, H.C.; GAUTZC, L. Shade coffee in Hawai'i - exploring some aspects of quality, growth, yield, and nutrition. Scientia Horticulturae, v.128, p.152-158, 2011. DOI: 10.1016/j.scienta.2011.01.011.

STEPHENSON, R.A.; GALLAGHER, E.C.; DOOGAN, V.J. Macadamia responses to mild water stress at different phenological stages. Australian Journal of Experimental Agriculture Research, v.54, p.67-75, 2003. DOI: 10.1071/AR02108.

VAAST, P.; BERTRAND, B.; PERRIOT, J.J.; GUYOT, B.; GÉNARD, M. Fruit thinning and shade improve bean characteristics and beverage quality of coffee (Coffea arabica L.) under optimal conditions. Journal of the Science of Food and Agriculture, v.86, p.197-204, 2006. DOI: 10.1002/jsfa.2338.

VIEIRA, C. Índice de equivalência de área. Informe Agropecuário, v.10, p.12-13, 1984.

WILLEY, R.W.; OSIRU, D.S.O. Studies on mixtures of maize and beans (Phaseolus vulgaris) with particular reference to plant population. Journal of Agricultural Science, v.79, p.517-529, 1972. DOI: $10.1017 /$ S0021859600025909.

Recebido em 15 de abril de 2014 e aprovado em 1ำ de dezembro de 2014 